\title{
MEMÓRIA DE RECONHECIMENTO SOCIAL EM RATOS
}

\author{
Paula J. Moura \\ Gilberto F. Xavier
}

\begin{abstract}
Resumo: O paradigma intruso-residente vem sendo intensamente empregado em estudos para avaliar a memória de reconhecimento social em roedores. Tipicamente, ratos adultos (residentes) são expostos a dois encontros de 5 minutos cada com um mesmo intruso juvenil ou com juvenis diferentes; o intervalo entre encontros é usualmente 30 minutos. A quantidade de comportamentos sociais do residente, no segundo encontro, em relação a um intruso familiar é substancialmente menor do que o observado no primeiro encontro, o que não ocorre quando o segundo encontro envolve um juvenil novo; esse resultado caracteriza memória de reconhecimento social. Neste estudo discutimos achados recentes sobre os tipos de comportamentos usualmente incluídos nas categorias social e não-social, a influência da fase temporal, a interferência de rotinas laboratoriais na memória de reconhecimento social, modalidades sensoriais usualmente empregadas por roedores no processamento de informações na memória social e alternativas adicionais para o estudo da socialidade em roedores.
\end{abstract}

Palavras-chave: Paradigma intruso-residente. Comportamento social. Rato. Comportamentos sociais investigativos. Comportamentos sociais agonísticos.

A investigação dos mecanismos fisiológicos, celulares e moleculares vinculados aos comportamentos sociais em modelos animais têm contribuído para o entendimento de comportamentos complexos como a relação de dominância-subordinação, comportamentos sexuais e os de agressão. Esses comportamentos têm como pano de fundo lembranças de encontros sociais passados, também conhecidas como memórias de reconhecimento social. 


\subsection{Comportamentos sociais e memória de reconhecimento social}

Relações sociais são construídas e mantidas a partir de interações entre indivíduos. $O$ reconhecimento de um indivíduo como integrante de um dado grupo social é fundamental para o funcionamento do grupo. Há vantagens adaptativas na formação de grupos sociais. Por exemplo, (1) animais em grupos são atacados menos frequentemente do que animais solitários, (2) o desgaste físico para alcançar e abater uma caça é menor, pois vários animais se engajam na busca e perseguição da presa resultando em maior eficiência, e (3) a convivência com animais senis proporciona aos mais jovens a aprendizagem, por imitação, de tarefas essenciais para a sobrevivência como a caça ou outras informações importantes como local de açudes que não secam em períodos de estiagem prolongada (Slater, 2000). Mecanismos envolvidos na construção e manutenção de relações sociais vêm sendo investigados em experimentos de laboratório por meio de tarefas que permitem controlar os fatores que interferem no estabelecimento dessas relações.

Tentativas sistemáticas de identificar comportamentos sociais em roedores levaram à categorização de interações definidas como comportamento de "luta" ("fighting behavior") (Davis, 1933; Hall \& Klein, 1942). Na década de 1960, estudos baseados também em observações comportamentais de animais definiram a postura "agressiva" (Grant \& Mackintosh, 1963). No mesmo ano, Grant (1963) realizou uma análise minuciosa das posturas observadas em encontros sociais de ratos entre 75 e 120 dias de idade, ao longo de sessões de 15 minutos, e relatou 60 tipos diferentes de posturas, incluindo as categorias "agressão" e "luta". Grant (1963) ressaltou a ocorrência de posturas representativas de "atividade deslocada" ("displacement activity"). Essas posturas aparentemente irrelevantes do ponto de vista da interação social eram assumidas pelos animais quando dois comportamentos não relacionados estavam fortemente estimulados concomitantemente, ou ainda em situações de frustração (Grant, 1963). Isto é, comportamentos como beber, comer, escavar, auto-catação ("self-grooming"), "postura de lado" em relação ao outro animal ("sideways posture"), entre outros, exibidos fora de seu contexto apropriado seriam, segundo Grant (1963), indicativos de "atividades deslocadas".

Posteriormente, sugeriu-se que os comportamentos sociais poderiam ser classificados em quatro categorias principais, incluindo comportamentos sociais de investigação, contato direto, comportamentos atentos ("attentive behaviors") e comportamentos "do tipo" agressivo. Os comportamentos sociais de investigação incluem aqueles nos quais um rato obtém informações sobre o outro cheirando e lambendo, ou mesmo utilizando suas vibrissas para obter informações de natureza tátil (Popik \& van Ree, 1998); nesses animais, a investigação anogenital parece extremamente im- 
portante para a aquisição de informações sobre o co-específico (Popik \& van Ree, 1998). Contatos sociais diretos incluem passar por cima ou por baixo do co-específico, montar e catação social ("social grooming") (Popik \& van Ree, 1998). Comportamentos atentos incluem aproximação e perseguição do co-específico. Comportamentos do tipo agressivo incluem mordiscadas,"chutes" e posturas ameaçadoras (Popik \& van Ree, 1998).

Atualmente, na tentativa de simplificar a análise dos comportamentos sociais em roedores de laboratório, têm-se observado o tempo que os animais permanecem próximos ao seu co-específico (Sekiguchi, Wolterink, \& van Ree, 1991b; Burman \& Mendl, 2000; Ferguson, Aldag, Insel, \& Young, 2001; Ferguson et al., 2000). Esse tipo de padronização simplifica a análise comportamental, inclusive pela possibilidade de se utilizar métodos automátizados de registro. Porém, ela limita a análise de informações sobre a natureza dos comportamentos eliciados no encontro social e seu possível significado, restringindo a compreensão dos fatores que contribuem para a interação social.

Tem sido comum, em estudos sobre memória de reconhecimento social, a observação dos padrões comportamentais exemplificados nas Figuras 1 e 2 .

A

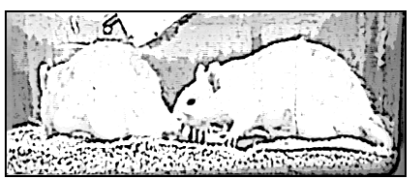

C

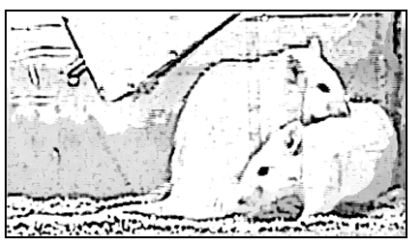

E

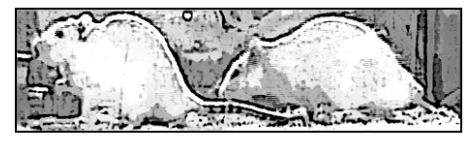

B

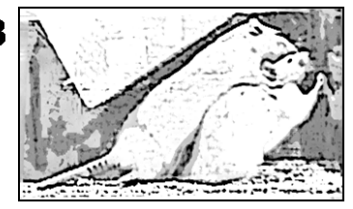

D

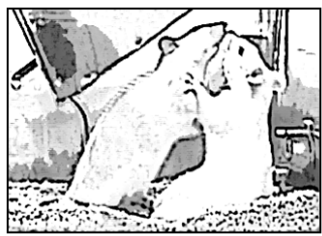

$\mathbf{F}$

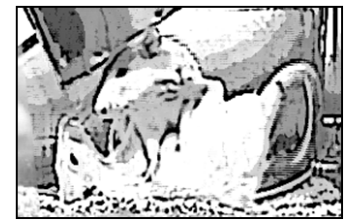

Figura 1. Fotografias exemplificando comportamentos sociais usualmente observados em estudos sobre memória de reconhecimento social. (A) Investigação anogenital (o rato da direita cheira e lambe a região anogenital do co-específico). (B) Investigação da cabeça (o rato da esquerda cheira e 
lambe a cabeça do animal da direita). (C) Investigação do corpo (o rato da esquerda cheira e lambe o corpo do animal da direita). (D) Comportamentos agressivos (o rato da esquerda exibe uma postura ameaçadora, conhecida como postura ereta ("upright") ou ataca o animal da direita). (E) Perseguir (o rato da direita caminha atrás do rato da esquerda buscando aproximar-se do mesmo). (F) Comportamento de dominância (o rato posicionado em cima do outroo segura em posição de subordinação com o dorso voltado ao solo).

Fonte: arquivo próprio.

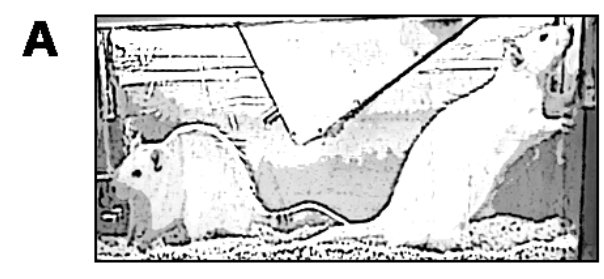

B
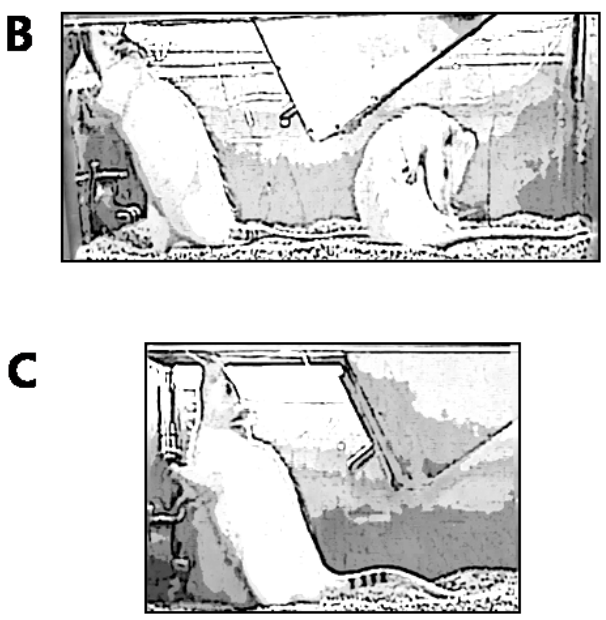

Figura 2. Fotografias exemplificando comportamentos não sociais usualmente observados em estudos sobre memória de reconhecimento social. (A) Cheirar o ambiente e levantar-se (o rato da esquerda cheira as paredes da caixa enquanto o da direita levanta-se nas patas posteriores, apoiando a pata anterior na parede da caixa). (B) Levantar-se e auto-catação (o rato da esquerda exibe comportamento de levantar-se nas patas posteriores apoiando a pata anterior na parede da caixa e o rato da direita exibe comportamentos de auto-catação). (C) Levantar-se (o rato apresenta comportamento de levantar-se nas patas posteriores, sem qualquer apoio das patas dianteiras).

Fonte: arquivo próprio. 
Moura, Meirelles e Xavier (submetido) e Moura, Venkitaramani, Tashev, Lombroso e Xavier (submetido) mostraram que a análise dos comportamentos exemplificados nas Figuras 1 e 2 permitem revelar a memória de reconhecimento social em ratos. Esses autores mostraram ainda que o tempo de exibição de alguns desses comportamentos durante a interação social difere em animais residentes e intrusos; animais residentes exibem maior quantidade de comportamentos sociais e animais intrusos exibem maior quantidade de comportamentos não sociais. Por fim, esses estudos mostraram que há vantagens em distinguir pelo menos duas sub categorias de comportamentos sociais, a primeira caracterizada pelos comportamentos sociais investigativos e a segunda pelos comportamentos sociais agonísticos, que são diferentemente afetadas pelos contatos sociais prévios (ver adiante). Muitos mamíferos exibem a habilidade de discriminar indivíduos da mesma espécie. Contudo, diferentes grupos de animais fazem uso de pistas distintas para esse reconhecimento. Humanos e primatas não humanos fazem uso preferencial de pistas visuais e auditivas para discriminar e identificar co-específicos; já roedores parecem basear-se principalmente em informações de natureza olfatória.

Nos últimos 60 anos foram realizados diversos estudos envolvendo memória de reconhecimento social em roedores de laboratório (Dantzer, Bluthe, Koob, \& Le Moal, 1987; Engelmann, Wotjak, \& Landgraf, 1995; Grant, 1963; Popik, Ventulani, Bisaga, \& van Ree, 1991; Thor \& Holloway, 1982). Esses estudos vêm mostrando que roedores são capazes de modular a quantidade de comportamentos sociais de acordo com a familiaridade com o co-específico. Ratos são também capazes de discriminar a maravalha usada (suja), i. e., previamente utilizada como forração de gaiola, oriunda de diferentes animais; por exemplo, são capazes de identificar maravalha usada oriunda de fêmeas e machos, e também maravalha usada oriunda de um animal cuja maravalha foi investigada anteriormente em relação à oriunda de um animal cuja maravalha usada nunca foi investigada (Sawyer, Hengehold, \& Perez, 1984). Esse tipo de resultado levou à sugestão de que roedores exibem "assinaturas olfatórias" (Carr, Yee, Gable, \& Marasco, 1976) que seriam cruciais para a formação de grupos sociais, e também na demarcação de territórios.

Há um consenso de que feromônios possuem propriedades importantes para a memória de reconhecimento social. Feromônios são secretados por glândulas localizadas em diferentes locais do corpo; em roedores, principalmente na região anogenital.Também tem sido sugerida a presença de feromônios na urina (Karlson \& Luscher, 1959). O reconhecimento do indivíduo por meio dessas substâncias parece possibilitar a formação de pares, reconhecimento de familiares e o estabelecimento de hierarquias de dominância (Ferguson, Young, \& Insel, 2002; Maaswinkel, Baars, Gispen, \& Spruijt, 1996; Young, 2002). 
Thor e Holloway (1982) mensuraram, em ratos, a quantidade de comportamentos sociais direcionada a um co-específico familiar ou desconhecido, e sugeriram que esse índice pode ser utilizado para investigar, indiretamente, a memória de reconhecimento social. Ratos sexualmente maduros, denominados residentes, foram expostos a dois encontros sucessivos, de 5 minutos cada, com um mesmo rato juvenil, denominado intruso; o intervalo de tempo entre os encontros foi 10, 20, 40 ou 80 minutos, em grupos independentes de animais. A quantidade de comportamentos sociais do residente em relação ao intruso no segundo encontro foi substancialmente menor em relação ao observado no primeiro encontro, quando o intervalo de tempo entre as sessões foi 40 minutos ou menos, mas não quando o intervalo de tempo foi 80 minutos. Num segundo experimento, esses autores avaliaram se essa redução da quantidade de comportamentos sociais estaria relacionada à identificação do intruso ou meramente a um fenômeno de habituação ou "fadiga social". Isso envolveu a exposição de ratos residentes a um primeiro encontro com um intruso juvenil, seguido de um segundo encontro com o mesmo intruso juvenil ou com um intruso juvenil diferente; o intervalo de tempo entre os encontros foi 10 minutos. O comportamento social dos residentes foi registrado no primeiro e no segundo encontros. Os residentes exibiram menor quantidade de comportamentos sociais (1) no segundo encontro com o intruso familiar em relação ao primeiro encontro com esse mesmo intruso, replicando os resultados do experimento anterior, e (2) no segundo encontro com um intruso familiar em relação a um segundo encontro envolvendo intruso diferente. Além disso, a quantidade de comportamentos sociais no segundo encontro envolvendo intruso diferente não diferiu daquela exibida no primeiro encontro. Juntos, esses resultados permitiram descartar a hipótese de que houve habituação ou fadiga social, sugerindo que o fenômeno está relacionado com a identificação do intruso previamente encontrado. Thor e Holloway (1982) mostraram também que a quantidade de comportamentos sociais exibida pelos intrusos juvenis foi substancialmente menor do que aquela exibida pelos residentes adultos e que os juvenis também revelaram memória de reconhecimento social; porém, a duração desta memória não ultrapassou cerca de 4 minutos. Depois desse estudo seminal, diversos outros autores passaram a utilizar o "paradigma intruso-residente", como ficou conhecido, para investigar a memória de reconhecimento social em roedores.

Diversos testes comportamentais têm fornecido indicações de que a memória de reconhecimento social em roedores envolve informações de natureza olfatória.

Por exemplo, o teste habituação-discriminação baseia-se no reconhecimento de co-específicos por meio de odores (Halpin, 1974). Numa primeira fase o animal é exposto a um odor de um co-específico até que ocorra habituação, identificada pela redução da investigação olfatória. Numa 
segunda fase, o animal é exposto concomitantemente ao odor familiar e a um odor desconhecido. Observa-se, usualmente, que os animais investigam mais o odor desconhecido, sendo capazes de discriminá-lo do familiar, após sucessivas apresentações deste último. No teste de discriminação condicional de odores oriundos de co-específicos (Bowers \& Alexander, 1967), os animais são recompensados quando respondem em presença de um odor e não recompensados quando respondem em presença do odor de outro co-específico.Se os animais aprendem a tarefa, depreende-se que são capazes de detectar e discriminar que os odores são diferentes. Note que este teste difere do teste de habituação-discriminação, já que a exposição a ambos os odores leva à habituação e à familiaridade, mas como apenas um dos odores sinaliza a possibilidade de otenção da recompensa quando há emissão da resposta, há necessidade de identificar qual é o odor presente. No teste de persistência do comportamento social investigativo observa-se que a persistência da investigação social de um co-específico é reduzida quando há exposição prévia ao odor oriundo do co-específico presente, em relação à investigação social direcionada a um co-específico presente cujo odor não foi apresentado previamente, sugerindo que o animal tenha detectado uma diferença entre os co-específicos (Carr, Krames, \& Costanzo, 1970; Sawyer, Hengehold, \& Perez, 1984). Também o "efeito de Bruce" ("Bruce effect"), i.e., o bloqueio gestacional observado quando uma fêmea prenhe é exposta ao odor de um macho que não corresponde ao seu par (Bruce, 1959; Bruce \& Parrott, 1960; Parkes \& Bruce, 1961), ressalta que roedores são capazes de realizar a discriminação social.

Uma das principais vantagens no uso deste tipo de testes comportamentais para investigar a memória relaciona-se ao fato de que a resposta dos animais independe de reforçadores ou punição imediatos do comportamento, dependendo apenas da tendência natural de ratos investigarem seus co-específicos (Gheusi, Bluthe, Goodall, \& Dantzer, 1994b; Thor \& Holloway, 1982; Gheusi, Bluthe, Goodall, \& Dantzer, 1994a). Comportamentos sociais manifestos ao longo de encontros sucessivos entre residentes e intrusos, separados por determinados intervalos de tempo, constituem a base do paradigma intruso-residente. Geralmente, o rato residente investiga vigorosamente o intruso durante o primeiro encontro e, no caso da formação de uma memória de reconhecimento social, há redução dos comportamentos sociais durante o segundo encontro com o mesmo intruso (Figura 3). Como vimos acima, esse efeito é dependente do intervalo de tempo entre o primeiro e o segundo encontros. 

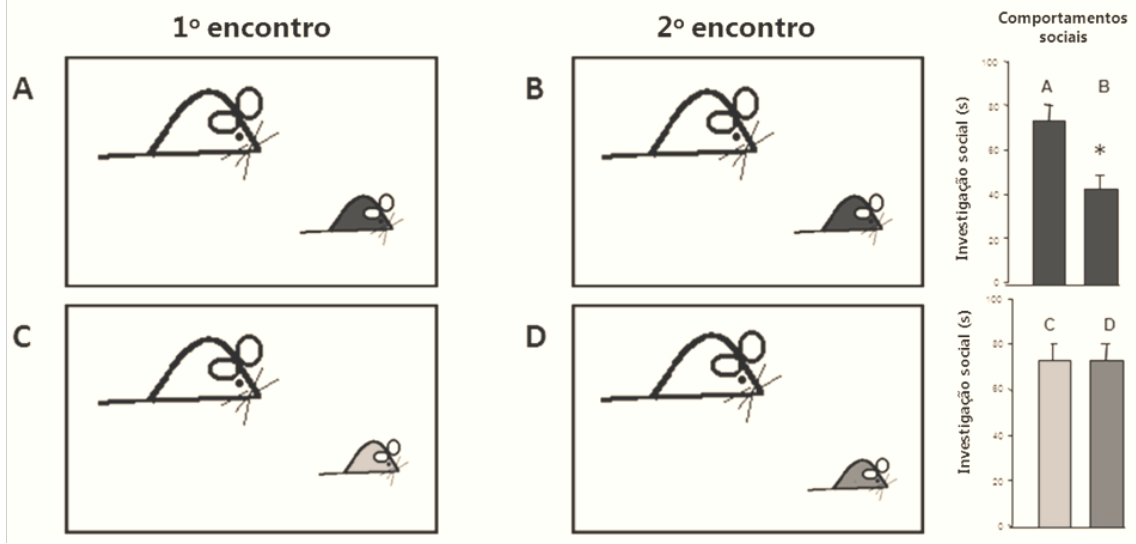

Figura 3. Representação esquemática do paradigma intruso-residente e dos resultados usualmente observados. Num primeiro encontro (A e C) um intruso (representado pelo roedor menor) é apresentado ao rato residente (representado pelo rato maior) ao longo de 5 minutos. Num segundo encontro, realizado 30-40 minutos depois, o mesmo intruso (B) ou um intruso diferente (D) é apresentado ao rato residente ao longo de 5 minutos. A quantidade de comportamentos sociais observados nessas condições experimentais é mostrada nos gráficos à direita. A redução da quantidade de comportamentos sociais do primeiro para o segundo encontros com o mesmo intruso (colunas A e $\mathbf{B}$, respectivamente) é interpretada como evidência de memória de reconhecimento social. A ausência de redução na quantidade de comportamentos sociais do primeiro para o segundo encontros com intrusos diferentes (colunas $\mathbf{C}$ e $\mathbf{D}$, respectivamente) sugere que o efeito anterior não está associado à habituação.

Fonte: arquivo próprio.

Há peculiaridades na memória de reconhecimento social que, aparentemente, a distingue de outros tipos de memória. Por exemplo, sua duração é maior do que a da memória operacional, mas menor do que uma memória do tipo espacial ou aversiva. Isso tem levado alguns autores a caracterizá-la como um tipo específico de memória, distinto de outros já descritos na literatura da área (Ferguson et al., 2002).

A literatura sobre memória de reconhecimento social em ratos assume que ela corresponde a um tipo de memória de curta duração, em função dos resultados obtidos no paradigma intruso-residente. Isto é, ratos residentes expostos por 5 minutos a um intruso exibem (1) redução dos comportamentos sociais quando o segundo encontro com o mesmo intruso é realizado cerca de 30 a 40 minutos depois e (2) a mesma quantidade de comportamentos sociais quando o segundo encontro com o mesmo 
intruso é realizado 2 horas ou mais depois. Esse tipo de resultado tem levado diversos autores a assumirem que a memória de reconhecimento social duraria cerca de 60 minutos (e.g., Dantzer et al., 1987; Dantzer, Koob, Bluthe, \& LeMoal, 1988; Popik et al. 1991; Sekiguchi, Wolterink, \& van Ree, 1991b; Sekiguchi et al., 1991a; Dantzer, Engelmann, \& Landgraf, 1994; Popik \& van Ree, 1998).

Houve tentativas de aumentar a duração da memória de reconhecimento social em ratos. Por exemplo, a duração do primeiro encontro com o intruso, usualmente de 5 minutos, foi aumentada pela inclusão de encontros adicionais, cada um deles de 5 minutos, realizados a intervalos de tempo variáveis, dependendo do estudo (e. g., Dantzer et al., 1987; Sekiguchi et al., 1991a; Squires, Peddle, Milway, \& Harley, 2006). Assim, a exposição do residente a dois encontros sucessivos de 5 minutos cada com o mesmo intruso levou a um aumento da duração da memória de reconhecimento social para 2 horas. Por outro lado, a exposição do residente a dois encontros sucessivos com intrusos distintos comprometeu a memória de reconhecimento social em relação ao primeiro intruso, mesmo quando o intervalo de tempo entre o primeiro e o terceiro encontros foi de apenas 30 minutos (Dantzer et al., 1987). Nesta mesma linha de raciocínio, Sekiguchi et al. (1991b) aumentaram a exposição ao intruso por meio do aumento da duração do primeiro encontro para 30 minutos ou por meio de seis encontros com duração de 5 minutos cada entremeados por intervalos de 10 minutos; a memória de reconhecimento social foi avaliada 24 horas depois. Em ambos os casos, não houve qualquer indício de memória de reconhecimento social. Sekiguchi et al. (1991b) realizaram 6 exposições por dia do mesmo intruso ao rato residente, cada exposição com 5 minutos de duração, ao longo de 4 dias; o teste foi realizado no quinto dia. Novamente, os animais não revelaram qualquer indício de reconhecimento do intruso quando o intervalo entre os encontros sociais durou 24 horas (Sekiguchi et al., 1991a; Sekiguchi et al., 1991b). Portanto, a exposição ao intruso por 30 minutos contínuos ou por 2 horas divididas em 6 encontros de 5 minutos cada por dia, ao longo de 4 dias, não aumentou a duração da memória de reconhecimento social para 24 horas.

Moura et al. (submetido), utilizando o paradigma intruso-residente, expuseram grupos independentes de ratos a um co-específico adulto por 0,083 (5 minutos), 0,5 (30 minutos), 2, 24 e 168 horas; 24 horas depois esses ratos foram apresentados ao mesmo intruso ou a um intruso diferente, numa sessão de 10 minutos. O tempo investido por cada animal exibindo comportamentos sociais, incluindo (1) investigação da região anogenital (ANO), (2) investigação da cabeça (HEA), (3) investigação do corpo (BOD), (4) perseguição do co-específico (FOL), (5) comportamentos de dominância (DOM), e (6) comportamentos agressivos (AGR) (neste último caso, que não comprometam a integridade física dos animais), e também comportamentos não sociais, incluindo (7) cheirar o ambiente (ENV), (8) levantar-se 
nas patas trasseiras (rearing) (REA) e (9) auto-catação (self-grooming) (GRO) foi registrado. Adicionalmente à tradicional análise de variância para medidas repetidas (ANOVA), os autores utilizaram uma análise de componentes principais ("Principal Component Analysis," PCA). No conjunto, os resultados demonstraram inequivocamente, e contrariamente ao preconizado na literatura dessa área, que ratos exibem memória de reconhecimento social que se mantém por pelo menos 24 horas, quando a duração do primeiro encontro é igual ou maior do que 2 horas de exposição contínua ao intruso adulto. Os resultados mostraram ainda que há vantagens na categorização dos comportamentos sociais em duas subcategorias, a de comportamentos sociais investigativos e a de comportamentos sociais agonísticos, sendo a primeira mais apropriada para se avaliar memória de reconhecimento social em ratos em relação à comumente adotada soma das duas. O presente estudo ressalta também a importância de se definir memória de reconhecimento social não apenas em função da redução da investigação social em direção ao intruso familiar, critério comumente adotado na literatura da área, mas também em função do aumento da investigação social em direção ao intruso diferente; ou seja, é da comparação da quantidade de comportamentos sociais investigativos direcionada aos intrusos familiar e diferente que se extrai informações seguras sobre a expressão da memória de reconhecimento social. Finalmente, este estudo revelou que a PCA se constitui numa ferramenta com grande potencial para revelar relações significativas entre as variáveis mensuradas neste tipo de estudo, que usualmente não são reveladas pela estatística tradicional.

\subsection{Memória de reconhecimento social e fase temporal}

É notória a existência de processos temporais envolvendo variáveis fisiológicas, neurais e comportamentais entre os seres vivos (Halberg, 1969). Diversos animais modificam seu comportamento ao longo do ciclo de 24 horas, exibindo uma alternância entre atividade e repouso. Não raro processos comportamentais complexos, incluindo aprendizagem e memória, sofrem influência desta variação circadiana (e.g., Davies, Navaratnam, \& Redfern, 1973; Holloway \& Wansley, 1973; Wansley, \& Holloway, 1976).

A influência de fatores temporais sobre a memória de reconhecimento social também foi objeto de investigações. Por exemplo, Reijmers, Leus e Burbach (2001) testaram ratos em diferentes momentos do ciclo claro-escuro, utilizando uma versão adaptada do paradigma intruso-residente. No primeiro encontro, os intrusos foram expostos aos residentes por 5 minutos. No segundo encontro, realizado 10 ou 25 minutos depois do primeiro, houve nova exposição de 5 minutos ao mesmo intruso ou a intrusos diferentes. Esses encontros foram conduzidos em quatro momentos diferentes do ciclo claro-escuro (nos "zeitgeber" 3, 9, 15 e 21). Os resultados 
obtidos nesse estudo levaram à conclusão de que não há modulação temporal sobre a memória de reconhecimento social em ratos.

Deve-se ressaltar, porém, que nesse estudo de Reijmers et al. (2001) houve marcada diferença nas condições fóticas em que animais de diferentes grupos foram testados. Isto é, animais testados na fase ativa encontravam-se no escuro e eram testados também no escuro, ao passo que animais testados na fase inativa encontravam-se expostos à luz, sendo testados também sob luz. Segundo Marques e Waterhouse (1994), a luz pode exercer um efeito inibitório na expressão de diferentes comportamentos em animais com hábitos de vida noturnos, permitindo questionar a comparabilidade dos resultados desses diferentes grupos. Em outras palavras, teria sido preferível realizar os testes em fases circadianas distintas, porém, em grupos de animais oriundos de condições fóticas similares. Outra possível restrição ao estudo de Reijmers et al. (2001) refere-se ao fato de que esses autores utilizaram apenas os intervalos de 10 ou de 25 minutos entre $o$ primeiro e o segundo encontros, i.e., intervalos de tempo que usualmente resultam no aparecimento da memória de reconhecimento social. Assim, os autores parecem ter partido do pressuposto de que haveria prejuízo da memória de reconhecimento social em determinados momentos do ciclo temporal, mas não consideraram a possibilidade de que pudesse haver aumento de sua duração dependendo do momento do ciclo temporal em que o teste foi realizado.

Pittendrigh (1965) descreveu uma condição experimental de controle temporal que possibilita a realização desse tipo de experimento: 0 fotoperíodo esqueleto. Isto é, ao invés de sincronizar os animais a um ritmo de 12 horas de claro e 12 horas de escuro, são usados dois pulsos de luz de 30 minutos cada nos extremos da fase ativa dos animais, entremeados de fases de 11 a 12 horas de luz tênue, para sincronizar os animais ao ciclo de 24 horas (Pittendrigh, 1965). Dessa forma animais de diferentes grupos podem ser testados em fases circadianas distintas, mas sob condições fóticas similares.

Moura, Gimenes-Júnior, Valentinuzzi e Xavier (2008) avaliaram se a memória de reconhecimento social é influenciada pela fase temporal do ritmo circadiano em que os testes são realizados. Grupos independentes de ratos sincronizados a um fotoperíodo esqueleto foram testados numa variante do paradigma de habituação-desabituação, em dois momentos diferentes do ciclo circadiano, sob as mesmas condições fóticas. A sincronização dos animais ao fotoperíodo esqueleto envolveu sua exposição a sucessivas sincronizações fóticas que incluíram, inicialmente, o ciclo claro/ escuro de 12/12 horas, a substituição da fase escura por luz tênue e, então, a introdução do fotoperíodo esqueleto. Esse esquema fótico garantiu a manutenção do ritmo de inatividade/atividade dos animais; porém, diferentes grupos testados nas fases inativa e ativa encontravam-se em condições fóticas idênticas. Assim, foi possível avaliar o desempenho dos diferentes 
grupos de animais em diferentes momentos do ciclo circadiano, porém, nas mesmas condições de iluminação, garantindo a comparabilidade dos resultados. Grupos independentes de ratos foram submetidos a cinco encontros com intrusos juvenis por dia, cada encontro com duração de 5 minutos, ao longo de 4 dias; o primeiro encontro de cada dia ocorreu duas horas depois do início da fase inativa para alguns grupos ou duas horas depois do início da fase ativa para outros grupos, e o intervalo de tempo entre os encontros de cada dia foi 30 ou 60 minutos, dependendo do grupo. No primeiro e segundo dias, o intruso juvenil apresentado foi o mesmo em cada encontro; diferentemente, no terceiro e quarto dias o intruso juvenil apresentado foi diferente em cada encontro. Os resultados mostraram que a expressão de comportamentos sociais está sujeita à modulação temporal. Além disso, essa modulação parece depender do intervalo de tempo entre os encontros, uma vez que os animais testados na fase inativa com intervalos de 60 minutos entre as sessões exibiram maior quantidade de comportamentos sociais em relação aos demais grupos. Assim, a modulação temporal deve ser levada em consideração no planejamento de experimentos para avaliar não apenas a memória de reconhecimento social, mas também a sociabilidade em ratos.

\subsection{Interferência na memória de reconhecimento social}

Rotinas laboratoriais podem influenciar o comportamento dos animais e também seu desempenho em testes de memória.

$\mathrm{O}$ isolamento social de ratos em idade precoce, além de crítico para o desenvolvimento do sistema nervoso, se reflete em diversos comportamentos do animal adulto (Anisman, Zaharia, Meaney, \& Merali, 1998; Caldji, Diorio, \& Meaney, 2000). Da mesma forma, o acondicionamento de apenas um animal por gaiola após o desmame induz significativas alterações no comportamento adulto (Einon \& Morgan, 1977; Jones, Robbins, \& Marsden, 1989). Alterações na reatividade emocional de roedores causadas pelo isolamento social têm reflexos na atividade locomotora (Gentsch, Lichtsteiner, Frischknecht, Feer, \& Siegfried, 1988; Wilkinson, Killcross, \& Humby, 1994; Domeney \& Feldon, 1998), defecação (Holson, Scallet, Ali, \& Turner, 1991), neofobia (Hall,Humby, Wilkinson, \& Hobbins, 1997a; Hall, Humby, Wilkinson, \& Hobbins, 1997b), aumento dos comportamentos agressivos em relação a co-específicos (Wongwitdecha \& Marsden, 1996), aumento dos comportamentos agressivos ao serem manipulados (Hatch, Balazs, Wilberg, \& Grice, 1963), no condicionamento de preferência a lugares (Coudereau, Debray, Monier, Bourre, \& Frances, 1997), na inibição pré-pulso ("pre-pulse inhibition") (Day-Wilson, Jones, Southam, Cilia, \& Torrerdell, 2006), no condicionamento clássico aversivo ao contexto (Rudy, 1996; Coudereau et al., 1997) e na memória espacial (Pacteau, Einon \& Sinden, 1989). Não surpreende, por- 
tanto, que ratos socialmente isolados vêm sendo utilizados como modelo para o estudo da ansiedade (Parker \& Morinan, 1986) e da neofobia.

Em estudos envolvendo o paradigma intruso-residente os residentes eventualmente são isolados socialmente por uma semana antes dos testes; alega-se que o objetivo dessa manipulação seja estimular os comportamentos sociais (Thor \& Holloway, 1982; Ferguson et al., 2001). Porém, tem havido relatos de que o isolamento social de camundongos pode prejudicar a aprendizagem e memória, inclusive a memória de reconhecimento social, particularmente quando o intervalo de tempo entre encontros é prolongado (Kogan, Frankland, \& Silva, 2000).

Burman e Mendel (2000) mostraram que determinadas rotinas laboratoriais podem influenciar o desempenho de ratos no paradigma intrusoresidente. Estes autores expuseram ratos a dois encontros sociais, cada qual com 5 minutos de duração, com um mesmo co-específico; o intervalo de tempo entre os encontros foi 15 minutos. Neste intervalo de tempo foram realizadas manipulações experimentais, ao longo de 5 minutos, iniciadas 5 minutos depois do primeiro encontro. Essas manipulações incluiram (1) segurar o animal na mão por 5 segundos a intervalos regulares de 15 segundos, (2) exposição a um novo intruso, (3) transferência para uma caixa menor onde permaneceram por 5 minutos, (4) transferência para uma caixa de mesmo tamanho onde permaneceram por 5 minutos e (5) ausência de manipulação, como condição controle. As condições 1, 2 e 3 levaram a prejuízos na memória de reconhecimento social. Os autores ressaltaram que nuances experimentais como o excesso ou mesmo a ausência de manipulação dos animais, a limpeza das gaiolas antes, durante ou após os experimentos, podem influenciar o desempenho dos animais.

Esses resultados ressaltam que rotinas laboratoriais devem ser cuidadosamente consideradas ao se planejar testes comportamentais para avaliar memória de reconhecimento social, uma vez que os resultados experimentais podem ser influenciados não apenas pelas variáveis que o experimentador julga controlar, mas também por variáveis sobre as quais nem sempre existe um controle explícito.

Moura et al. (submetido), baseados na demonstração de Moura et al. (submetido) de que ratos exibem memória de reconhecimento social com duração de pelo menos 24 horas, hipotetizaram que a ausência de relatos anteriores sobre a existência de memória de reconhecimento social de longa duração em ratos poderia estar relacionada à interferência retroativa gerada pelo transporte dos animais residentes da sala de experimentação para o biotério, depois da primeira experiência com o intruso. Para avaliar essa hipótese, os autores expuseram ratos residentes a um co-específico adulto por 2 horas e, então, transportaram esses animais para o biotério 0,5 ou 6 horas depois do término desse primeiro encontro. Vinte e quatro horas depois, os residentes foram expostos a um segundo encontro com intrusos familiares ou diferentes. Os resultados mostraram inequivocamente 
que o transporte dos animais da sala de experimentos para o biotério 0,5 horas após o primeiro encontro prejudica a memória de reconhecimento social dos animais, o que não ocorre quando o transporte é realizado 6 horas depois. Esses resultados indicam que deve haver cautela no planejamento de experimentos envolvendo a memória de reconhecimento social que requerem o transporte dos animais da sala de experimentação para o biotério; como esse tipo de procedimento é parte da rotina da maioria dos laboratórios que realizam estudos comportamentais, é importante ter em mente que esse transporte pode influenciar a memória e o desempenho dos animais.

\subsection{Aspectos relevantes da memória de reconhecimento social}

A investigação dos processos neurais subjacentes aos comportamentos sociais tem se valido de diferentes métodos experimentais. A definição clara e precisa de um teste comportamental para avaliar determinado conjunto de funções é condição fundamental para se entender seus processos neurobiológicos subjacentes.

Aparentemente, a memória de reconhecimento social pode ser caracterizada como uma entidade única. Diferentes laboratórios vêm defendendo que ela se baseia proponderantemente em informações de natureza olfatória (Ferguson et al., 2000; Ferguson et al., 2002; Dantzer et al., 1988).

\subsubsection{Processamento de informações sociais: ação de feromônios?}

Nos últimos 50 anos diversos estudos mostraram uma estreita relação entre pistas olfatórias, comportamentos sociais e memória de reconhecimento social; embora haja relatos de que os sentidos visual e auditivo (especialmente a vocalização ultra-sônica) também contribuem para essas funções (Lore \& Flannelly, 1977; Sales, 1991), há relativamente poucas informações sobre a natureza dessa contribuição. A maioria das pesquisas na área de memória de reconhecimento social em roedores focaliza o sistema olfatório. Duas grandes classes de informações olfatórias são citadas: feromônios e "outros odorantes".

Feromônios são substâncias secretadas por indivíduos que geram reações específicas, quase estereotipadas, em co-específicos (Karlson \& Luscher, 1959). Há duas classes de feromônios identificadas pelo seu peso molecular, uma delas volátil, com baixo peso molecular, e a outra não volátil, com alto peso molecular. Respostas neuroendócrinas que resultam em aceleração da puberdade ou mesmo bloqueio gestacional (Bruce \& Parrott, 1960) são estimuladas por componentes contidos na urina de coespecíficos do sexo oposto. Comportamentos sociais como atração sexual, ou seleção sexual de um indivíduo e agressão estão vinculados às pistas químico-sensoriais de outro co-específico (Johnston, 1998; Keverne, 1999). 
Roedores exibem dois sistemas para o processamento de informações olfatórias, o sistema olfatório principal e o sistema olfatório acessório. Os receptores do sistema olfatório acessório localizam-se no órgão vomeronasal, enquanto os receptores do sistema olfatório principal situam-se no epitélio olfatório. Até meados da década de 90 , postulava-se que o sistema olfatório acessório teria sido selecionado ao longo da adaptação à vida terrestre, e seria dedicado exclusivamente à detecção de informações feromonais; diferentemente, o sistema olfatório principal seria responsável pelo processamento de informações sobre demais odorantes (Dulac \& Torello, 2003; Moncho-Bogani, Lanuza, Hernandez, \& Novejarque, 2002; Moncho-Bogani, Martinez-Garcia, Novejarque \& Lanuza, 2005). Nos últimos anos esse postulado vem sendo questionado. Por exemplo, Baxi, Dorries e Eisthen (2006) argumentaram que só é possível admitir que há equivalência entre processamento vomeronasal e processamento feromonal se se demonstrar (1) que os sinais químicos feromonais são processados exclusivamente pelo sistema vomeronasal e (2) que o sistema vomeronasal não medeia outra função que não o processamento feromonal. Porém, vem sendo demonstrado que o sistema vomeronasal responde também a estímulos não feromonais (Buck, 2000; Sam et al., 2001; Trinh \& Storm, 2003). Similarmente, informações feromonais também são detectadas pelo epitélio olfatório. Por exemplo, a secreção vaginal de fêmeas de hamster contém feromônios que eliciam comportamentos sexuais no macho, induzem síntese de proteína c-fos no núcleo medial da amígdala e área pré-óptica, áreas envolvidas na iniciação da cópula. A destruição do epitélio olfatório, mas não do órgão vomeronasal, elimina esse aumento da expressão de $c$-fos nessas regiões, indicando que o sistema olfatório principal medeia essas respostas (Swann, Rahaman, Bijak, \& Fiber, 2001). Além disso, tem havido descrições de que, em camundongos, ambos os sistemas olfatórios, o principal e o acessório, são estimulados por feromônios e outros odores (Xu et al., 2005).

Baxi, Dorris e Eisthen (2006) propuseram que moléculas maiores, não voláteis, seriam detectadas pelo órgão vomeronasal; diferentemente, moléculas mais leves, voláteis, seriam processadas pelo epitélio olfatório. Entretanto, há evidências de que moléculas menores também poderiam ser detectadas pelo órgão vomeronasal, quando estivessem ligadas a uma molécula maior. Roedores exibem uma proteína urinária principal ("major urinary protein" - MUP) que atuaria como veículo olfatório para pequenas moléculas voláteis. Isto é, estas últimas alcançariam o epitélio olfatório por meio da ligação com essa proteína não volátil que, então, ativaria o órgão vomeronasal. Pouco se sabe sobre como esse complexo seria formado; admite-se a existência de duas moléculas feromonais voláteis em camundongos machos, excretadas na urina, a 2,3-dehydro-exo-brevicomin (DHB) e a 2-sec-butyl-4,5-dihydrothiazole (SBT), que se ligam à MUP (Bacchini, Gaetani \& Cavaggioni, 1992). Haveria uma outra MUP com alta afinidade 
ao SBT na mucosa nasal, o que sugere que um ou ambos os feromônios são transportados ao órgão vomeronasal quando ligados às proteínas, explicando, assim, o feromônio ser considerado uma molécula não volátil (Sharrow, Vaughn, Zidek, Novotny, \& Stone, 2002). Tanto a DHB quanto a SBT estimulam o bulbo olfatório acessório apenas na presença das MUPs (Guo, Zhou, \& Moss, 1997); porém, tem havido relatos de que porções diferentes do bulbo olfatório acessório são estimuladas pelos feromônios voláteis e MUPs (Brennan, Schellinck, \& Keverne, 1999). A DHB e a SBT parecem capazes de eliciar respostas de neurônios do órgão vomeronasal mantidos in vitro. E as MUPs também parecem exercer funções vinculadas ao reconhecimento individual (Hurst et al., 2001). Porém, não está claro se a DHB e a SBT são parte do complexo não volátil com a MUP quando eles entram no órgão vomeronasal, ou se a presença das MUPs é necessária para a estimulação do sistema vomeronasal pela DHB e a SBT.

Luo, Fee e Katz (2003) investigaram a atividade unitária de neurônios do bulbo olfatório acessório de camundongos machos, durante a investigação social; os disparos neuronais foram modulados pelo contato físico do macho com a fêmea. Isto é, para obter informações feromonais parece necessário que os animais cheirem ativamente o co-específico, estabelecendo contato; ademais, a apresentação de um camundongo artificial, que faculta contato mas não possui cheiro, não foi suficiente para eliciar resposta destes mesmos neurônios.

Também o padrão de ativação neuronal de camundongos fêmeas expostos ao odor de machos vem sendo investigado, considerando a experiência prévia das mesmas (Moncho-Bogani et al., 2005). Fêmeas ingênuas nunca expostas ao odor de macho apresentam expressão de $c$-fos no núcleo basal da amígdala apenas quando mantêm contato direto com forragem usada da gaiola de machos; diferentemente, quando expostas apenas aos odores voláteis advindos da maravalha, sem o contato direto com a mesma, não houve ativação dessa região nervosa. Interessantemente, fêmeas com experiência prévia ao odor de machos, por exposição direta ou indireta (contato com a forragem usada) apresentam ativação não só do núcleo basal da amígdala, mas de outras regiões nervosas sabidamente envolvidas no sistema de recompensa (Moncho-Bogani et al., 2005). Esses dados sugerem que a associação entre odores voláteis e não voláteis ocorrida no primeiro encontro contribui para a ativação de estruturas do sistema de recompensa no segundo encontro (Moncho-Bogani et al., 2005). Supostamente, informações sobre odores voláteis oriundos do sistema olfatório principal alcançariam regiões como o núcleo basal da amígdala, via conexões com o córtex entorrinal e córtex piriforme, e seriam integradas com informações sobre odores feromonais não voláteis, oriundas do sistema olfatório acessório, que chegariam ao núcleo basal da amígdala por conexões diretas (porção póstero-medial do núcleo cortical) e indiretas (núcleo posterior da amígdala). 
Assim, o processamento de informações sociais não parece depender exclusivamente da informação feromonal, pois parece haver um processamento extremamente complexo, envolvendo várias fontes de informação. Aparentemente, ambos os sistemas olfatórios contribuem para a identificação de um co-específico como familiar ou não. Ademais, roedores não se valem exclusivamente de informações de natureza olfatória para a identificação de co-específicos; outros sentidos e outras regiões encefálicas não diretamente relacionadas à olfação também contribuem para o reconhecimento social.

1.4.2 Regiões nervosas relacionadas à memória de reconhecimento social em roedores

A amígdala tem sido associada ao reconhecimento social de roedores (Maaswinkel et al., 1996; Ferguson et al., 2001). A amígdala é uma estrutura heterogênea, constituída de vários núcleos que podem ser classificados anatomicamente,estruturalmente e funcionalmente (Swanson \& Petrovich, 1998). Funcionalmente a amígdala pode ser dividida em quatro grandes grupos: sistema olfatório acessório, sistema olfatório principal, sistema olfatório autonômico e sistema fronto-temporal (Swanson \& Petrovich, 1998).

O sistema olfatório acessório é composto pelo órgão vomeronasal, bulbo olfatório acessório e suas projeções (1) diretas para estruturas como o núcleo medial da amígdala e região póstero-medial do núcleo cortical da amígdala, e (2) indiretas para amígdala posterior, hipotálamo medial, subiculum ventral, insula agranular e porção medial do córtex pré-frontal (de Olmos, Hardy, \& Heimer, 1978; Moncho-Bogani et al., 2002; Swanson \& Petrovich, 1998). Entre as estruturas do sistema olfatório acessório, apenas o núcleo posterior da amígdala não está envolvido diretamente no processamento de informações provenientes do órgão vomeronasal; diferentemente, o núcleo medial da amígdala parece estar fortemente envolvido no processamento de informações oriundas dessa estrutura (Canteras, Simerly, \& Swanson, 1995; de Olmos et al., 1978; Meredith \& Westberry, 2004; Moncho-Bogani et al., 2002; Swanson \& Petrovich, 1998).

O sistema olfatório principal integra informações advindas do epitélio olfatório, que seguem para o bulbo olfatório principal que, por sua vez, se projeta diretamente para as porções póstero-lateral e anterior do núcleo cortical da amígdala, área de transição pós-piriforme e área amígdalo-piriforme, e indiretamente para núcleo posterior da amígdala, porção posterior do núcleo basolateral, accumbens e hipocampo, entre outras (Swanson \& Petrovich, 1998).

O núcleo medial da amígdala de roedores vem sendo associado ao comportamento maternal (Fleming, Suh, Korsmie, \& Rusak, 1994; Fleming,Vaccarino, \& Luebke, 1980; Sheehan, Paul, Amaral, Numan, \& Numan, 2001), comportamento sexual (Coolen, Peters, \& Veening, 1997; Do- 
minguez \& Hull, 2004; Harris \& Sachs, 1975; Lehman \&Winans, 1982; Lehman, Winans, \& Powers 1980; Petrulis \& Johnston, 1999; Rajendren \& Moss, 1993), comportamento de dominância ("agonistic") (Bolhuis, Fitzgerald, Dijk, \& Koolhaas, 1984; Kollack-Walker \& Newman, 1995; Koolhaas, Schuurman, \& Wiepkema 1980; Luiten, Koolhas, de Boer, \& Koopmans, 1985), comportamento de defesa (Savonenko, Filipkowski, Werka, Zielinski, \& Kaczmarek, 1999), comportamento agressivo (Vochteloo \& Koolhaas, 1987), comportamento social (Stark et al., 1998) e reconhecimento social (Ferguson et al., 2001; Ferguson et al., 2000).

Estudos envolvendo a indução de danos seletivos e a expressão de genes, em roedores, possibilitaram a inclusão de outras regiões nervosas no esquema dos circuitos neurais possivelmente envolvidos na memória de reconhecimento social; entre elas citamos a região retrohipocampal (Bannerman et al. 2002), hipocampo (Squires et al., 2006), as fibras da via perfurante (Lemaire, Bohme, Piot, Roques, \& Blanchard, 1994), septo medial (Fournier et al. 1993; Terranova, Perio, Worms, Le Fur, \& Soubrie, 1994) e regiões frontais (córtex orbitofrontal e giro cingulado anterior). É interessante notar que essas regiões estão direta ou indiretamente relacionadas com regiões que recebem aferências dos bulbos olfatórios.

1.4.3 Neurotransmissores que modulam a memória de reconhecimento social

Diversos estudos associam a oxitocina e vasopressina a processos de memória (Bielsky \& Young, 2004; Dantzer, 1998; de Wied, 1965; de Wied, 1976; de Wied, Van, Wimersma Greidanus, \& Bohus, 1974; de Wied, Van Wimersma Greidanus, Bohus, Urban, \& Gispen, 1976; Ferguson et al., 2000; Insel \& Shapiro, 1992).

A vasopressina e a oxitocina são nonapeptídeos que se distinguem por apenas um aminoácido, sendo encontrados exclusivamente em mamíferos. Ambos são sintetizados no hipotálamo que, por meio de projeções axônicas, atingem a neurohipófise. Há relatos de que também regiões extra-hipotalâmicas produzem esses peptídeos (de Vries \& Buijs, 1983). A vasopressina e a oxitocina são considerados hormônios endócrinos na periferia (a oxitocina está envolvida na contração uterina durante o trabalho de parto e também na ejeção de leite em fêmeas) e neurotransmissores/ neuromoduladores centralmente; e seriam imprescindíveis para a memória de reconhecimento social em roedores (Insel, 1997).

Parcela significativa dos experimentos que associa a ação central da vasopressina à memória de reconhecimento social tem sido conduzida em roedores (Dantzer et al., 1987; Engelmann \& Landgraf, 1994; Everts \& Koolhaas, 1997; Ferguson et al., 2001; Ferguson et al., 2000; Popik \& van Ree, 1998; van Wimersma Greidanusvan, Ree, \& de Wied, 1983; Young, 2002; Young, Pitkow, \& Ferguson, 2002). 
A administração sistêmica de vasopressina e oxitocina em ratos promove um aumento da duração da memória de reconhecimento social; Dantzer et al. (1987) mostraram que ratos submetidos à administração de vasopressina logo após o primeiro encontro com um co-específico exibiram redução da quantidade de comportamentos sociais ao mesmo coespecífico, mas não a um co-específico diferente, num segundo encontro realizado 2 horas depois. Interessantemente, se ao invés de vasopressina administra-se um bloqueador de oxitocina, os animais perdem a capacidade de reconhecer o intruso mesmo quando o segundo encontro é realizado 30 minutos depois do primeiro encontro.

Também administração intra-cerebro-ventricular ou tópica desses neurotransmissores na região septal-lateral, hipocampo ventral e dorsal, bulbo olfatório, altera a memória de reconhecimento social (van Wimersma Greidanus \& Maigret, 1996; Dluzen et al., 1998; Le Moal, Dantzer, Michaud, \& Koob, 1987; Engelmann \& Landgraf, 1994; Engelmann, Wotjak, Ebner, \& Landgraf, 2000). Isto é, a maioria dos estudos mostram que a vasopressina facilita o processamento da memória de reconhecimento social (Dantzer et al., 1987; de Wied et al., 1976; Engelmann \& Landgraf, 1994; Popik \& van Ree, 1998; van Wimersma Greidanus \& Maigret, 1996). Diferentemente, enquanto altas doses de oxitocina atenuam a memória de reconhecimento social, doses próximas aos níveis fisiológicos a facilitam (Popik \& Vetulani, 1991; Popik Vetulani, \& van Ree, 1992).

Ratos Brattleboro, que não sintetizam vasopressina, testados no paradigma intruso-residente exibem prejuízo na memória de reconhecimento social; isto é, a quantidade de investigação social do intruso familiar e do intruso novo no segundo encontro não difere independentemente do intervalo de tempo entre o primeiro e segundo encontros (Engelmann \& Landgraf, 1994). Interessantemente, a administração de vasopressina no septo dorsolateral destes animais restabelece o reconhecimento social típico, ou seja, há redução da investigação social quando os animais são reexpostos ao intruso familiar até 60 minutos depois do primeiro encontro. Assim, a deficiência de vasopressina no septo dorsolateral parece crítica para a memória de reconhecimento social em ratos.

Outras estuturas nervosas também parecem envolvidas nessa função. Por exemplo, os níveis de vasopressina no septo lateral influenciam a memória de reconhecimento social (Bielsky, Hu, Ren, Terwilliger, \& Young, 2005; Dantzer et al. 1988). Além disso, enquanto a micro-injeção de vasopressina no hipocampo dorsal bloqueia o reconhecimento de machos da mesma espécie, micro-injeções no bulbo olfatório em ratos machos meIhoram o reconhecimento de co-específicos (Dluzen, Muraoka, Engelmann \& Landgraf, 1998a; Dluzen, Muraoka, \& Landgraf, 1998b).

A administração tópica de oxitocina e de vasopressina no septo dorsolateral e no bulbo olfatório potencializa a memória de reconhecimento social (Popik, Vos, \& Van Ree, 1992). Por outro lado, a administração de bai- 
xas doses de oxitocina, mas não de vasopressina, na área pré-óptica medial potencializa a memória de reconhecimento social (Popik, Vetulani, \& van Ree, 1992; Ferguson et al., 2002).

Manipulações genéticas permitiram gerar camundongos que não produzem oxitocina, mas que exibem os receptores específicos para este neurotransmissor. Estes animais exibem marcada deficiência da memória de reconhecimento social (Ferguson et al., 2000), não obstante sua audição, olfação e orientação espacial não exibirem quaisquer alterações significativas. A administração de oxitocina no núcleo medial da amígdala, mas não no bulbo olfatório, antes, mas não depois, de encontros sociais, levaram à recuperação da memória de reconhecimento social.

Estudos envolvendo genes de expressão imediata em camundongos "knockout" de oxitocina expostos a encontros sociais com co-específicos revelam a ocorrência de maior expressão de c-fos no núcleo cortical da amígdala, córtex piriforme e septo dorsolateral; diferentemente, em camundongos normais, há maior expressão de c-fos no núcleo medial da amígdala, núcleo intersticial da estria terminal e área pré-óptica medial (Ferguson et al., 2001). O significado destes resultados ainda não está totalmente claro.

\subsection{Alternativas adicionais para o estudo da socialidade em roedores}

Dentre as alternativas interessantes para se investigar a sociabilidade, incluem-se os arganazes (Figuras 5A e 5B), animais que apresentam subgrupos com comportamentos sociais um tanto distintos. Arganazes do campo (Microtus ochrogaster) são altamente sociáveis, monogâmicos e cuidam da prole. Diferentemente, arganazes da montanha (Microtus montanus) são a-sociais, poligâmicos e não cuidam da prole. Ao comparar essas duas espécies filogeneticamente próximas, Young (2002) observou diferenças na distribuição de receptores dos neuropeptídeos oxitocina e vasopressina que, como vimos, estão relacionados a comportamentos sociais, nos encéfalos destes roedores. Arganazes do campo apresentam maior quantidade de receptores de oxitocina no núcleo accumbens e complexo basolateral da amígdala; em contrapartida, arganazes da montanha apresentam maior quantidade desses receptores no septo lateral (Insel \& Shapiro, 1992). Receptores de vasopressina do subtipo V1a são encontrados em maior quantidade nos arganazes do campo, no pálido ventral e núcleo medial da amígdala; já em arganazes da montanha esses receptores situam-se principalmente no septo lateral (Lim, Murphy, \& Young, 2004; Insel \& Shapiro, 1992; Young, 2002). Aparentemente, essa localização distinta desses receptores no encéfalo pode levar à ativação de circuitos neurais distintos e, consequentemente, induzir respostas comportamentais diferentes. Em outras palavras, os arganazes da montanha, por não contarem com a 
ativação de regiões encefálicas fortemente relacionadas ao sistema de recompensa, não exibiriam motivação para o contato social.

Esse modelo tem levado a especulações sobre as bases neuroanatomo-funcionais de pessoas com distúrbios sociais, como no caso de autistas. Pesquisas mostram que o gene que produz o receptor $\mathrm{V} 1 \mathrm{a}$ em arganazes exibe semelhanças em relação ao gene AVPR1a de seres humanos, havendo indícios apontando que autistas exibem alterações neste gene.
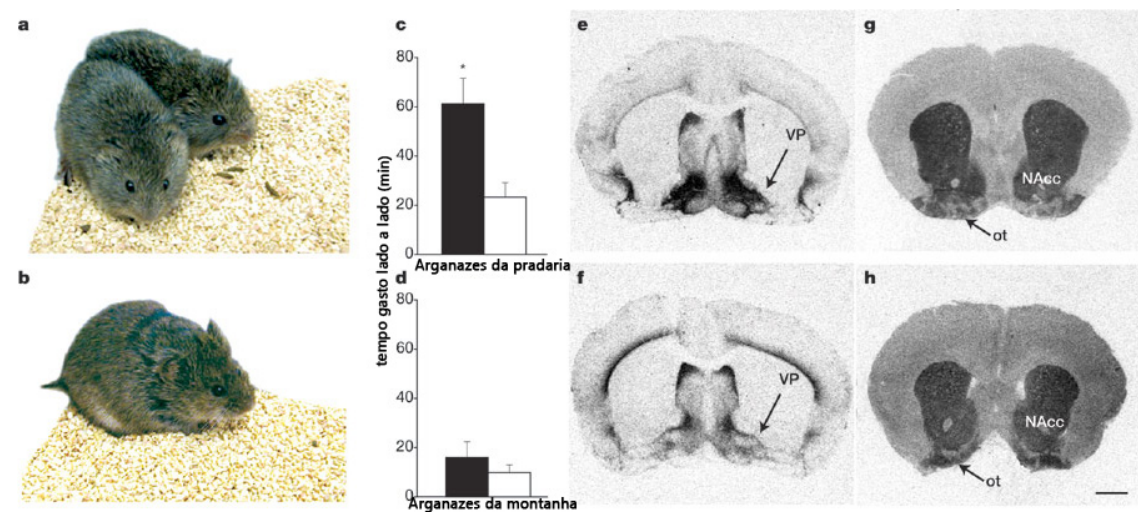

Figura 4. Arganazes do campo (A) e da montanha (B). Arganazes da montanha e do campo são similares na aparência, porém os do campo são altamente afiliativos, preferindo investir maior parte do tempo ao lado de um co-específico. (C) Após cruzamento e co-habitação com uma fêmea, o arnagaz macho do campo investe maior quantidade de tempo em contato com a parceira (coluna preta) do que com uma fêmea desconhecida (coluna branca) $(p<0.05)$. (D) Diferentemente, arganazes da montanha não exibem preferência pela parceira, investindo relativamente pouco tempo ao lado de uma fêmea familiar ou uma nova. (E) e (F) Autoradiogramas ilustrando o encéfalo típico de um arganaz do campo e da montanha, respectivamente. São evidentes as diferenças entre arganazes do campo e da montanha no padrão de distribuição do receptor de vasopressina. (G) e (H) Interessantemente, a distribuição dos receptores de dopamina são similares nessas duas espécies.

Fonte: Alterado de Lim et al. (2004).

Um modelo comportamental descrito recentemente para o estudo da memória de reconhecimento social envolve expor um hamster "residente" macho a outros dois machos, um deles separado por uma grade metálica, evitando assim o contato direto, mas permitindo o trânsito de informações olfatórias, visuais e auditivas, e o outro diretamente na caixa 
experimental, o que permite contato direto, inclusive com o aparecimento de disputas territoriais que permitem identificar um "ganhador" e um "perdedor" da disputa. Vinte e quatro horas depois dessa primeira exposição, os residentes "perdedores" são testados num labirinto em "Y"; no final de um dos braços é colocado o animal "ganhador" e no final do outro braço é colocado o animal exposto separadamente pela grade. Os residentes "perdedores" preferem o braço do labirinto contendo o animal apresentado separadamente pela grade ao invés daquele com o qual ele teve contato direto e para o qual já perdeu uma disputa territorial (Lai, Ramiro, Yu, \& Johnston, 2005), revelando a memória de reconhecimento social.

Também a preferência alimentar transferida socialmente vem sendo empregada em estudos sobre a memória de reconhecimento social. Neste teste dois animais são agrupados pelos dois dias que antecedem os testes, com o intuito torná-los familiares. Um dos animais, denominado demonstrador, é privado de ração para estimular seu apetite. No momento dos testes, o demonstrador é transferido para outra sala e recebe, ao longo de 30 minutos, ração com odor de chocolate ou canela. Logo a seguir, o demonstrador é pareado com o outro rato, denominado observador, por 15 minutos. Então, o observador, agora transferido para uma caixa de testes, é exposto às duas rações, a experimentada pelo demonstrador e a outra. O observador apresenta marcada preferência pela ração consumida pelo demonstrador. Testes adicionais revelam que esse efeito não está relacionadao à palatibilidade ou odor dos alimentos, nem à exposição prévia ao seu odor, e sim ao pareamento do alimento ingerido pelo demonstrador e o encontro social com o mesmo (Galef, Wigmore, \& Kennett, 1983).

\section{Conclusão}

Há mais de 25 anos o paradigma intruso-residente tem sido o teste preferido para estudos sobre a memória de reconhecimento social em roedores, apesar da crença generalizada, até recentemente, de que o mesmo permite avaliar apenas a memória de reconhecimento social de curta duração (até cerca de 2 horas).

De fato, esse teste apresenta vantagens para o estudo de memória de reconhecimento social em roedores, pois (1) a aquisição da informação crítica ocorre em um único encontro com o co-específico e a avaliação da memória de reconhecimento social envolve apenas uma sessão de teste, i.e., um segundo encontro com o mesmo ou outro co-específico, (2) o teste envolve a tendência natural dos animais de interagirem socialmente, sem a necessidade de estímulação aversiva ou privação alimentar ou de água para indução da aprendizagem, (3) as exigências materiais para a realização dos experimentos são relativamente pequenas e (4) sua aplicação é relativamente simples. 
A demonstração de que a memória de reconhecimento social pode ser mantida por pelo menos 24 horas, correspondendo, portanto, a um teste relevante para o estudo de memória de longa duração (Moura et al., submetido; Moura et al, submetido), associada à descoberta de que rotinas laboratoriais corriqueiras, como o transporte dos animais de volta ao biotério entre encontros sociais, podem influenciá-la, dependendo do intervalo de tempo de permancência na sala de experimentos antes do transporte (Moura et al, submetido), enfatizam que seus mecanismos subjacentes exibem um curso temporal definido passível de interferencia. Essas demonstrações abrem diversas possibilidades de investigação sobre os processos subjacentes a essa função crucial, por meio de manipulações farmacológicas, neurais e comportamentais, que poderão contribuir para nossa compreensão acerca dos processos básicos envolvidos na memória e na socialidade. Isso poderá contribuir também para o desenvolvimento de modelos animais voltados para estudos psiquiátricos relacionados a alterações nas relações sociais como a esquizofrenia e o autismo.

\title{
Social recognition memory in rats
}

\begin{abstract}
The intruder-resident paradigm has been extensively employed in studies of social recognition memory in rodents. Typically, adult rats (residents) are exposed to two 5-min encounters with the same juvenile intruder or with two different juveniles; the interval between the encounters is $30 \mathrm{~min}$. The amount of social behaviors exhibited by the resident rats toward the same intruder juvenile in the second encounter is substantially smaller when compared to both that seen in the first encounter and that seen toward a different juvenile; these results characterize social recognition memory. In this study we discuss recent findings related to behaviors usually included as social and non-social, the influence of the temporal phase on social behavior, the interference of laboratory routines on social recognition memory, sensory modalities usually employed by rodents for processing relevant information in the social memory and additional alternatives to study sociability in these animals.
\end{abstract}

Keywords: Intruder-resident paradigm. Social behavior. Rats. Social investigative behaviors. Social agonistic behaviors.

\section{Mémoire de reconnaissance sociale chez les rats}

Résumé: Le paradigme intrus-résident a été employée dans les études de memoire de reconnaissance social chez les rongeurs. Les rats adultes, nommés résidents, sont exposés à deux rencontres de 5 min chacun, avec un même intrus juvénile ou avec des différents. L'intervalle de temps parmi les rencontres est 30 min. Le montant des comportements sociaux du résident, à la deuxième rencontre, par 
rapport a un intrus familiaire est sensiblement inférieur à celui observé à la première rencontre, ce qui ne se produit pas lorsque la deuxième recontre implique un nouveau juvenil. Ce résultat caractérise la mémoire de reconnaissance social. Cette étude discute des récentes conclusions du comportement social et non social, l'influence de la phase temportelle, l'ingérence dês routines de laboratoire dans cette memoire, les modalités sensorielles habituellement utilisées par les rongeurs dans le traitement de l'information sociale dans la mémoire et des solutions alternatifs pour l'étude de la socialité chez eux.

Mots clés: Paradigme résident-intrus. Comportement social. Rats. Enquête sociale des comportements. Comportements sociaux agonistiques.

\section{Memoria de reconocimiento social en ratones}

Resumen: El paradigma intruso-residente se viene utilizando extensivamente en estudios de memoria de reconocimiento social en roedores. Típicamente, un ratón adulto (residente) se expone a dos encuentros de 5 minutos cada uno con el mismo intruso juvenil o con dos juveniles diferentes; el intervalo entre los encuentros es de 30 minutos. El número de comportamientos sociales en el segundo encuentro exhibido por el residente y direccionado hacia el mismo intruso es substancialmente menor comparado con el primer encuentro o con un intruso nuevo; este tipo de disminución comportamental caracteriza memoria de reconocimiento social. En este estudio discutimos nuevos resultados relacionados con los comportamientos sociales y no-sociales, influencia de la fase circadiana, interferencia de las rutinas de laboratorio en la memoria de reconocimiento social, modalidades sensoriales empleadas por roedores para procesar información relevante a la memoria social y las alternativas adicionales para estudiar sociabilidad en estos animales.

Palabras clave: Paradigma intruso-residente. Comportamiento social. Ratones. Comportamientos de investigación social. Comportamientos agonísticos sociales.

\section{Referências}

Anisman, H., Zaharia, M. D., Meaney, M. J., \& Merali, Z. (1998). Do early-life events permanently alter behavioral and hormonal responses to stressors? International Journal of Developmental Neuroscience, 16, 149-164.

Bacchini, A., Gaetani, E., \& Cavaggioni, A. (1992). Pheromone binding proteins of the mouse, Mus musculus. Experientia, 48, 419-421. 
Bannerman, D. M., Lemaire, M., Yee, B. K., Iversen, S. D., Oswald, C. J., Good, M. A., \& Rawlins, J. N. (2002). Selective cytotoxic lesions of the retrohippocampal region produce a mild deficit in social recognition memory. Experimental Brain Research. Experimentelle Hirnforschung, 142, 395-401.

Baxi, K. N., Dorries, K. M., \& Eisthen, H. L. (2006). Is the vomeronasal system really specialized for detecting pheromones? Trends in Neurosciences, 29, 1-7.

Bielsky, I. F., Hu, S. B., Ren, X., Terwilliger, E. F., \& Young, L. J. (2005). The V1a vasopressin receptor is necessary and sufficient for normal social recognition: A gene replacement study. Neuron, 47, 503-513.

Bielsky, I. F., \& Young, L. J. (2004). Oxytocin, vasopressin, and social recognition in mammals. Peptides, 25, 1565-1575.

Bolhuis, J. J., Fitzgerald, R. E., Dijk, D. J., \& Koolhaas, J. M. (1984). The corticomedial amygdala and learning in an agonistic situation in the rat. Physiology \& Behavior, $32,575-579$.

Bowers, J. M., \& Alexander, B. K. (1967). Mice: Individual recognition by olfactory cues. Science, 158, 1208-1210.

Brennan, P. A., Schellinck, H. M., \& Keverne, E. B. (1999). Patterns of expression of the immediate-early gene egr-1 in the accessory olfactory bulb of female mice exposed to pheromonal constituents of male urine. Neuroscience, 90, 1463-1470.

Bruce, H. M. (1959). An exteroceptive block to pregnancy in the mouse. Nature, 184, 105-105.

Bruce, H. M., \& Parrott, D. M. (1960). Role of olfactory sense in pregnancy block by strange males. Science, 131, 1526-1526.

Buck, L. B. (2000). The molecular architecture of odor and pheromone sensing in mammals. Cell, 100, 611-618.

Burman, O. H., \& Mendl, M. (2000). Short-term social memory in the laboratory rat: Its susceptibility to disturbance. Applied Animal Behaviour Science, 67, 241-254.

Caldji, C., Diorio, J., \& Meaney, M. J. (2000). Variations in maternal care in infancy regulate the development of stress reactivity. Biological Psychiatry, 48, 1164-1174.

Canteras, N. S., Simerly, R. B., \& Swanson, L. W. (1995). Organization of projections from the medial nucleus of the amygdala: A PHAL study in the rat. The Journal of Comparative Neurology, 360, 213-230. 
Carr, E. J., Yee, L., Gable, D., \& Marasco, M. (1976). Olfactory recognition of conspecifics by domestic Norway rats. Journal of Comparative \& Physiological Psychology, 90, 821-828.

Carr, W. J., Krames, L., \& Costanzo, D. J. (1970). Previous sexual experience and olfactory preference for novel versus original sex partners in rats. Journal of Comparative \& Physiological \& Psychology, 71, 216-222.

Coolen, L. M., Peters, H. J., \& Veening, J. G. (1997). Distribution of Fos immunoreactivity following mating versus anogenital investigation in the male rat brain. Neuroscience, $77,1151-1161$.

Coudereau, J. P., Debray, M., Monier, C., Bourre, J. M., \& Frances, H. (1997). Isolation impairs place preference conditioning to morphine but not aversive learning in mice. Psychopharmacology, 130, 117-123.

Dantzer, R. (1998). Vasopressin, gonadal steroids and social recognition. Progress in Brain Research, 119, 409-414.

Dantzer, R., Bluthe, R. M., Koob, G. F., \& Le Moal, M. (1987). Modulation of social memory in male rats by neurohypophyseal peptides. Psychopharmacology, 91, 363-368.

Dantzer, R., Bluthe, R. M., \& LeMoal, M. (1988). Experimental assessment of drug-induced changes in cognitive function: Vasopressin as a case study. Neurotoxicology, 9, 471-477.

Dantzer, R., Engelmann, M., \& Landgraf, R. (1994). Microdialysis administration of vasopressin into the septum improves social recognition in Brattleboro rats. Physiology \& Behavior, 55, 145-149.

Dantzer, R., Koob, G. F., Bluthe, R. M., \& Le Moal, M. (1988). Septal vasopressin modulates social memory in male rats. Brain Research, 457, 143-147.

Davies, J. A., Navaratnam, V., \& Redfern, P. H. (1973). A 24-hour rhythm in passiveavoidance behaviour in rats. Psychopharmacologia, 32, 211-214.

Davis, F. C. (1933). The measurement of aggressive behavior in laboratory rats. The Jounal of Genetic Psychology, 43, 213-217.

Day-Wilson, K. M., Jones, D. N., Southam, E., Cilia, J., \& Totterdell, S. (2006). Medial prefrontal cortex volume loss in rats with isolation rearing-induced deficits in prepulse inhibition of acoustic startle. Neuroscience, 141, 1113-1121. 
de Olmos, J., Hardy, H., \& Heimer, L. (1978). The afferent connections of the main and the accessory olfactory bulb formations in the rat: An experimental HRP-study. The Journal of Comparative Neurology, 181, 213-244.

de Vries, G. J., \& Buijs, R. M. (1983). The origin of the vasopressinergic and oxytocinergic innervation of the rat brain with special reference to the lateral septum. Brain Research, 273, 307-317.

de Wied, D. (1965). The influence of the posterior and intermediate lobe of the pituitary and the pituitary peptides on the maintenance of a conditioned avoidance responses in rats. International Journal of Neuropharmacology, 4, 157167.

de Wied, D. (1976). Behavioral effects of intraventricularly administered vasopressin and vasopressin fragments. Life Sciences, 19, 685-690.

de Wied, D., Van Wimersma Greidanus, T. B., \& Bohus, B. (1974). The rat supraopticneurohypophyseal system and behavior: Role of vasopressin in memory processes. Problemes Actuels D'endocrinologie et de Nutrition, (Serie 18), 323-328.

de Wied, D., Van Wimersma Greidanus, T. B., Bohus, B., Urban, I., \& Gispen, W. H. (1976). Vasopressin and memory consolidation. Progress in Brain Research, 45, 181-194.

Dluzen, D. E., Muraoka, S. Engelmann, M., \& Landgraf, R. (1998). The effects of infusion of arginine vasopressin, oxytocin, or their antagonists into the olfactory bulb upon social recognition responses in male rats. Peptides, 19, 999-1005.

Dluzen, D. E., Muraoka, S. \& Landgraf, R. (1998). Olfactory bulb norepinephrine depletion abolishes vasopressin and oxytocin preservation of social recognition responses in rats. Neuroscience Letters, 254, 161-164.

Domeney, A., \& Feldon, J. (1998). The disruption of prepulse inhibition by social isolation in the Wistar rat: how robust is the effect? Pharmacology, Biochemistry, and Behavior, 59, 883-890.

Dominguez, J. M., \& Hull, E. M. (2004). Medial amygdala regulates mating-induced dopamine release in medial preoptic area. Annals of the New York Academy of Science, 985, 515-518.

Dulac, C., \& Torello, A. T. (2003). Molecular detection of pheromone signals in mammals: From genes to behaviour. Nature Reviews, 4, 551-562.

Einon, D. F., \& Morgan, M. J. (1977). A critical period for social isolation in the rat. Developmental Psychobiology, 10, 123-132. 
Engelmann, M., \& Landgraf, R. (1994). Microdialysis administration of vasopressin into the septum improves social recognition in Brattleboro rats. Physiology \& Behavior, 55, 145-149.

Engelmann, M., Wotjak, C. T., Ebner, K., \& Landgraf, L. (2000). Behavioural impact of intraseptally released vasopressin and oxytocin in rats. Experimental Physiology, 85(Spec), 125S-130S.

Engelmann, M., Wotjak, C. T., \& Landgraf, R. (1995). Social discrimination procedure: An alternative method to investigate juvenile recognition abilities in rats. Physiology \& Behavior, 58, 315-321.

Everts, H. G., \& Koolhaas, J. M. (1997). Lateral septal vasopressin in rats: Role in social and object recognition? Brain Research, 760, 1-7.

Ferguson, J. N., Aldag, J. M., Insel, T. R., \& Young, L. J. (2001). Oxytocin in the medial amygdala is essential for social recognition in the mouse. Journal of Neuroscience, $21,8278-8285$.

Ferguson, J. N., Young, L. J., Hearn, E. F., Matzuk, M. M., Insel, T. R., \& Winslow, J. T. (2000). Social amnesia in mice lacking the oxytocin gene. Nature Genetics, 25, 284-288.

Ferguson, J. N., Young, L. J., \& Insel, T. R. (2002). The neuroendocrine basis of social recognition. Frontiers in Neuroendocrinology, 23, 200-224.

Fleming, A. S., Suh, E. J., Korsmit, M., \& Rusak, B. (1994). Activation of Fos-like immunoreactivity in the medial preoptic area and limbic structures by maternal and social interactions in rats. Behavioral Neuroscience, 108, 724-734.

Fleming, A. S., Vaccarino, F., \& Luebke, C. (1980). Amygdaloid inhibition of maternal behavior in the nulliparous female rat. Physiology \& Behavior, 25, 731-743.

Fournier, J., Steinberg, R., Gauthier, T., Keane, P. E., Guzzi, U., Coude, F. X. et al. (1993). Protective effects of SR 57746A in central and peripheral models of neurodegenerative disorders in rodents and primates. Neuroscience, 55, 629-641.

Galef, B. G., Jr., Wigmore, S. W., \& Kennett, D. J. (1983). A failure to find socially mediated taste aversion learning in Norway rats (R. norvegicus). Journal of Comparative Psychology, 97, 358-363.

Gentsch, C., Lichtsteiner, M., Frischknecht, H. F., Feer, H., \& Siegfried, B. (1988). Isolation-induced locomotor hyperactivity and hypoalgesia in rats are prevented by handling and reversed by resocialization. Physiology \& Behavior, 43, 13-26. 
Gheusi, G., Bluthe, R. M., Goodall, G., \& Dantzer, R. (1994a). Ethological study of the effects of tetrahydroaminoacridine (THA) on social recognition in rats. Psychopharmacology, 114, 644-650.

Gheusi, G., Bluthe, R. M., Goodall, G., \& Dantzer, R. (1994b). Social and individual recognition in rodents: methodological aspects and neurobiological bases. Behavioural Process, 33, 59-87.

Grant, E. C. (1963). An analysis of the social behaviour of the male laboratory rat Behaviour, 21, 260-281.

Grant, E. C., \& Mackintosh, J. H. (1963). A description on the social postures of some laboratory rodents. Animal Behavior, 21, 246-253.

Guo, J., Zhou, A., \& Moss, R. L. (1997). Urine and urine-derived compounds induce c-fos mRNA expression in accessory olfactory bulb. Neuroreport, 8, 1679-1683.

Halberg, F. (1969). Chronobiology. Annual Review of Physiology, 31, 675-725.

Hall, C. S., \& Klein, S. J. (1942). Individual differences in aggressiveness in rats. Journal of Comparative Psychology, 33, 371-371.

Hall, F. S., Humby, T., Wilkinson, L. S., \& Robbins, T. W. (1997a). The effects of isolationrearing of rats on behavioural responses to food and environmental novelty. Physiology \& Behavior, 62, 281-290.

Hall, F. S., Humby, T., Wilkinson, L. S., \& Robbins, T.W. (1997b). The effects of isolation-rearing on preference by rats for a novel environment. Physiology \& Behavior, 62, 299-303.

Halpin, Z. T. (1974). Individual differences in the biological odors of the Mongolian gerbil (Meriones unguiculatus). Behavioral Biology, 11, 253-259.

Harris, V. S., \& Sachs, B. D. (1975). Copulatory behavior in male rats following amygdaloid lesions. Brain Research, 86, 514-508.

Hatch, A., Balazs, T., Wiberg, G. S., \& Grice, H. C. (1963). Long-term isolation stress in rats. Science, 142, 507-507.

Holloway, F. A., \& Wansley, R. A. (1973). Multiple retention deficits at periodic intervals after active and passive avoidance learning. Behavioral Biology, 9, 1-14.

Holson, R. R., Scallet, A. C., Ali, S. F., \& Turner, B. B. (1991). "Isolation stress" revisited: isolation-rearing effects depend on animal care methods. Physiology \& Behavior, 49, 1107-1118.

Psıcologia USP, São Paulo, abril/junho, 2010, 21(2), 355-389. 
Hurst, J. L., Payne, C. E., Nevison, C. M., Marie, A. D., Humphries, R. E., Robertson, D. H. et al. (2001). Individual recognition in mice mediated by major urinary proteins. Nature, 414, 631-634.

Insel, T. R. (1997). A neurobiological basis of social attachment. The American Journal of Psychiatry, 154, 726-735.

Insel, T. R., \& Shapiro, L. E. (1992). Oxytocin receptor distribution reflects social organization in monogamous and polygamous voles. Proceedings of the National Academy of Sciences of the United States of America, 89, 5981-5985.

Johnston, R. E. (1998). Pheromones, the vomeronasal system, and communication. From hormonal responses to individual recognition. Annals of the New York Academy of Sciences, 855, 333-348.

Jones, G. H., Robbins, T. W., \& Marsden, C. A. (1989). Isolation-rearing retards the acquisition of schedule-induced polydipsia in rats. Physiology \& Behavior, 45, 71-77.

Karlson, P., \& Luscher, M. (1959). Pheromones: A new term for a class of biologically active substances. Nature, 183, 55-56.

Keverne, E. B. (1999). The vomeronasal organ. Science, 286, 716-720.

Kogan, J. H., Frankland, P. W., \& Silva, A. J. (2000). Long-term memory underlying hippocampus-dependent social recognition in mice. Hippocampus, 10, 47-56.

Kollack-Walker, S. \& Newman, S. W. (1995). Mating and agonistic behavior produce different patterns of Fos immunolabeling in the male Syrian hamster brain. Neuroscience, 66, 721-736.

Koolhaas, J. M., Schuurman, T., \& Wiepkema, P. R. (1980). The organization of intraspecific agonistic behaviour in the rat. Progress in Neurobiology, 15, 247-268.

Lai, W. S., Ramiro, L. L., Yu, H. A., \& Johnston, R. E. (2005). Recognition of familiar individuals in golden hamsters: A new method and functional neuroanatomy. Journal of Neuroscience, 25, 11239-11247.

Lazar, J., Rasmussen, L. E., Greenwood, D. R., Bang, I. S., \& Prestwich, G. D. (2004). Elephant albumin: A multipurpose pheromone shuttle. Chemistry \& Biology, 11, 1093-1100.

Le Moal, M., Dantzer, R., Michaud, B., \& Koob, G. F. (1987). Centrally injected arginine vasopressin (AVP) facilitates social memory in rats. Neuroscience Letters, 77, 353359. 
Lehman, M. N., \& Winans, S. S. (1982). Vomeronasal and olfactory pathways to the amygdala controlling male hamster sexual behavior: Autoradiographic and behavioral analyses. Brain Research, 240, 27-41.

Lehman, M. N., Winans, S. S., \& Powers, J. B. (1980). Medial nucleus of the amygdala mediates chemosensory control of male hamster sexual behavior. Science, 210, 557-560.

Lemaire, M., Bohme, G. A., Piot, O, Roques, B. P., \& Blanchard, G. C. (1994). CCK-A and CCK-B selective receptor agonists and antagonists modulate olfactory recognition in male rats. Psychopharmacology, 115, 435-340.

Lim, M. M., Murphy, A. Z., \& Young, L. J. (2004). Ventral striatopallidal oxytocin and vasopressin $\mathrm{V} 1$ a receptors in the monogamous prairie vole (Microtus ochrogaster). The Journal of Comparative Neurology, 468, 555-570.

Lore, R., \& Flannelly, K. (1977). Rat societies. Scientific American, 236, 106-116.

Luiten, P. G., Koolhaas, J. M., Boer, S., \& Koopmans, S. J. (1985). The cortico-medial amygdala in the central nervous system organization of agonistic behavior. Brain Research, 332, 283-297.

Luo, M., Fee, M. S., \& Katz, L. C. (2003). Encoding pheromonal signals in the accessory olfactory bulb of behaving mice. Science, 299, 1196-1201.

Maaswinkel, H., Baars, A. M., Gispen, A. H., \& Spruijt, B. M. (1996). Roles of the basolateral amygdala and hippocampus in social recognition in rats. Physiology \& Behavior, 60, 55-63

Marques, M. D., \& Waterhouse, J. M. (1994). Masking and the evolution of circadian rhythmicity. Chronobiology International, 11, 146-155.

Meredith, M., \& Westberry, J. M. (2004). Distinctive responses in the medial amygdala to same-species and different-species pheromones. Journal of Neuroscience, 24, 5719-5725.

Moncho-Bogani, J., Lanuza, E., Hernandez, A., Novejarque, A., \& Martinez-Garcia, F. (2002). Attractive properties of sexual pheromones in mice: Innate or learned? Physiology \& Behavior, 77, 167-176.

Moncho-Bogani, J., Martinez-Garcia, F., Novejarque, A., \& Lanuza, E. (2005). Attraction to sexual pheromones and associated odorants in female mice involves activation of the reward system and basolateral amygdala. The European Journal of Neuroscience, 21, 2186-2198. 
Mrosovsky, N. (1988). Phase response curves for social entrainment. Journal of Comparative Physiology, 162, 35-46.

Pacteau, C., Einon, D., \& Sinden, J. (1989). Early rearing environment and dorsal hippocampal ibotenic acid lesions: Long-term influences on spatial learning and alternation in the rat. Behavioural Brain Research, 34, 79-96.

Parker, V., \& Morinan, A. (1986). The socially-isolated rat as a model for anxiety. Neuropharmacology, 25, 663-664.

Parkes, A. S., \& Bruce, H. M. (1961). Olfactory stimuli in mammalian reproduction. Science, 134, 1049-1054.

Petrulis, A., \& Johnston, R. E. (1999). Lesions centered on the medial amygdala impair scent-marking and sex-odor recognition but spare discrimination of individual odors in female golden hamsters. Behavioral Neuroscience, 113, 345-357.

Pittendrigh, C. S. (1965). On the mechanism of entrainment of circadian rhythms by light cycles. In J. Aschoff (Ed.), Circadian Clocks (p. 277). Amsterdam: North Holland.

Popik, P., \& van Ree, J. M. (1998). Neurohypophyseal peptides and social recognition in rats. Progress in Brain Research, 119, 415-436.

Popik, P., \& Vetulani, J. (1991). Opposite action of oxytocin and its peptide antagonists on social memory in rats. Neuropeptides, 18, 23-27.

Popik, P., Vetulani, J., Bisaga, A., \& van Ree, J. M. (1991). Recognition cue in the rat's social memory paradigm. Journal of Basic and Clinical Physiology and Pharmacology, 2, 315-327.

Popik, P., Vetulani, J., \& van Ree, J. M. (1992). Low doses of oxytocin facilitate social recognition in rats. Psychopharmacology, 106, 71-74.

Popik, P., Vos, P. E., \& Van Ree, J. M. (1992). Neurohypophyseal hormone receptors in the septum are implicated in social recognition in the rat. Behavioural Pharmacology, 3, 351-358.

Rajendren, G., \& Moss, R. L. (1993). The role of the medial nucleus of amygdala in the mating-induced enhancement of lordosis in female rats: The interaction with luteinizing hormone-releasing hormone neuronal system. Brain Research, 617, 8186. 
Reijmers, L. G., Leus, I. E., Burbach, J. P., Spruijt, B. M., \& van Ree, J. M. (2001). Social memory in the rat: Circadian variation and effect of circadian rhythm disruption. Physiology \& Behavior, 72, 305-309.

Rudy, J. W. (1996). Postconditioning isolation disrupts contextual conditioning: an experimental analysis. Behavioral Neuroscience, 110, 238-246.

Sales, D. G. (1991). The effect of $22 \mathrm{kHz}$ calls and artificial $38 \mathrm{kHz}$ signals on activity in rats. Behavioural Processes, 24, 83-93.

Sam, M., Vora, S., Malnic, B., Ma, W., Novotny, M. V., \& Buck, L. B. (2001). Neuropharmacology. Odorants may arouse instinctive behaviours. Nature, 412, 142-142.

Savonenko, A., Filipkowski, A. K., Werka, T., Zielinski, K., \& Kaczmarek, L. (1999). Defensive conditioning-related functional heterogeneity among nuclei of the rat amygdala revealed by c-Fos mapping. Neuroscience, 94, 723-733.

Sawyer, T. F., Hengehold, A. K., \& Perez, A. (1984). Chemosensory and hormonal mediation of social memory in male rats. Behavioral Neuroscience, 98, 908-913.

Sekiguchi, R., Wolterink, G., \& van Ree, J. M. (1991a). Analysis of the influence of vasopressin neuropeptides on social recognition of rats. European Neuropsychopharmacology, 1, 123-126.

Sekiguchi, R., Wolterink, G., \& van Ree, J. M. (1991b). Short duration of retroactive facilitation of social recognition in rats. Physiology \& Behavior, 50, 1253-1256.

Sharrow, S. D., Vaughn, J. L., Zidek, L. Novotny, M. V., \& Stone, M. J. (2002). Pheromone binding by polymorphic mouse major urinary proteins. Protein Science, 11, 22472256.

Sheehan, T., Paul, M., Amaral, E., Numan, M. J., \& Numan, M. (2001). Evidence that the medial amygdala projects to the anterior/ventromedial hypothalamic nuclei to inhibit maternal behavior in rats. Neuroscience, 106, 341-356.

Slater, P. J. B. (2000). El comportamiento animal. Madrid: Cambridge.

Squires, A. S., Peddle, R., Milway, S. J., \& Harley, C. W. (2006). Cytotoxic lesions of the hippocampus do not impair social recognition memory in socially housed rats. Neurobiology of Learning and Memory, 85, 95-101. 
Stark, C. P., Alpern, H. P., Fuhrer, J., Trowbridge, M. G. Wimbish, H., \& Smock, T. (1998). The medial amygdaloid nucleus modifies social behavior in male rats. Physiology \& Behavior, 63, 253-259.

Swann, J., Rahaman, F., Bijak, T., \& Fiber, J. (2001). The main olfactory system mediates pheromone-induced fos expression in the extended amygdala and preoptic area of the male Syrian hamster. Neuroscience, 105, 695-706.

Swanson, L. W., \& Petrovich, G. D. (1998). What is the amygdala? Trends in Neurosciences, 21, 323-331.

Terranova, J. P., Perio, A., Worms, P., Le Fur, G., \& Soubrie, P. (1994). Social olfactory recognition in rodents: Deterioration with age, cerebral ischaemia and septal lesion. Behavioural Pharmacology, 5, 90-98.

Thor, D. H., \& Holloway, W. R. (1982). Social memory of the male laboratory rat. Journal of Comparative and Physiological Psychology, 96, 1000-1006.

Trinh, K., \& Storm, D. R. (2003). Vomeronasal organ detects odorants in absence of signaling through main olfactory epithelium. Nature Neuroscience, 6, 519-525.

van Wimersma Greidanus, T. B., \& Maigret, C. (1996). The role of limbic vasopressin and oxytocin in social recognition. Brain Research, 713, 153-159.

van Wimersma Greidanus, T. B., van Ree, J. M., \& de Wied, D. (1983). Vasopressin and memory. Pharmacology \& Therapeutics, 20, 437-458.

Vochteloo, J. D., \& Koolhaas, J. M. (1987). Medial amygdala lesions in male rats reduce aggressive behavior: Interference with experience. Physiology \& Behavior, 41, 99102.

Wansley, R. A., \& Holloway, F. A. (1976). Oscillations in retention performance after passive-avoidance training. Learning and Motivation, 7, 296-302.

Wilkinson, L. S., Killcross, S. S., Humby, T., Hall, F. S., Geyer, M. A., \& Robbins, T. W. (1994). Social isolation in the rat produces developmentally specific deficits in prepulse inhibition of the acoustic startle response without disrupting latent inhibition. Neuropsychopharmacology, 10, 61-72.

Wongwitdecha, N., \& Marsden, C. A. (1996). Social isolation increases aggressive behaviour and alters the effects of diazepam in the rat social interaction test. Behavioural Brain Research, 75, 27-32. 
Xu, F., Schaefer, M., Kida, I., Schafer, J., Liu, N., Rothman, D. L., et al. (2005). Simultaneous activation of mouse main and accessory olfactory bulbs by odors or pheromones. The Journal of Comparative Neurology, 489, 491-500.

Young, L. J. (2002). The neurobiology of social recognition, approach, and avoidance. Biological Psychiatry, 51, 18-26.

Young, L. J., Pitkow, L. J., \& Ferguson, J. N. (2002). Neuropeptides and social behavior: Animal models relevant to autism. Molecular Psychiatry, 7(Suppl 2), S38-S39.

Paula Jaqueline de Moura, Mestre em Distúrbios do Desenvolvimento pela Universidade Mackenzie, Doutora em Ciências (Fisiologia Geral) pela Universidade de São Paulo. Rua do Matão, Travessa 14, 101. CEP: 05508-900. São Paulo, SP.Endereço eletrônico: paulajmoura@gmail.com

Gilberto Fernando Xavier, Professor Associado e Chefe do Laboratório de Neurociências e Comportamento, Instituto de Biociências, Universidade de São Paulo. Rua do Matão, Travessa 14, 101. CEP: 05508-900. São Paulo, SP. Endereço eletrônico: gfxavier@usp.br

Recebido em: $13 / 11 / 2008$

Aceito em: 30/03/2009 
